\title{
Multiplicação de bastão-do-imperador em resposta a concentrações de BAP e número de subcultivos ${ }^{(1)}$
}

\author{
EDER DE OLIVEIRA SANTOS ${ }^{(2)}$; ANTÔNIO ANDERSON DE JESUS RODRIGUES ${ }^{(3)}$ \\ ESDRAS ROCHA DA SILVA(2) e ANA CRISTINA PORTUGAL PINTO DE CARVALHO(4)
}

\begin{abstract}
RESUMO
O grande potencial ornamental das flores tropicais vem estimulando o cultivo comercial de várias espécies. A micropropagação é um método alternativo viável de propagação, pois possibilita a obtenção de um maior número de mudas com uniformidade e livres de patógenos. O objetivo do trabalho foi avaliar a taxa de multiplicação in vitro de Etlingera elatior cv. Porcelana, utilizando explantes obtidos a partir de brotações de mudas estabelecidas in vitro, obtidas do segundo subcultivo. Os explantes foram inoculados em meio de cultura MS contendo diferentes concentrações de BAP $(0,0 ; 2,22 ; 4,44 ; 6,66 ; 8,88$; e $11,10 \mu \mathrm{M})$, sendo as culturas mantidas em sala de crescimento com temperatura de $25,0 \pm 2,0{ }^{\circ} \mathrm{C}$ sob fotoperíodo de 12 horas de luz e intensidade luminosa de $30 \mu \mathrm{mol} \mathrm{m} \mathrm{m}^{-2} \mathrm{~s}^{-1}$. A taxa de multiplicação foi avaliada mensalmente, de acordo com os quatro subcultivos, totalizando 120 dias. O delineamento experimental foi o inteiramente casualizado, com quatro repetições, analisado em esquema fatorial 4 x 6 . Os dados foram submetidos à análise de variância e à regressão. Houve diferença significativa nos subcultivos efetuados e para as concentrações de BAP utilizadas. No primeiro subcultivo a concentração de $2,22 \mu \mathrm{M}$ de BAP proporcionou uma taxa de 4,06 brotos por explante, já no segundo e quarto subcultivos, com o acréscimo da concentração da citocinina houve aumento na quantidade de brotos alcançando a uma taxa de 4,05 e 4,96 brotos/explante na maior concentração testada de BAP. Os resultados dos tratamentos avaliados indicam que a presença de BAP favoreceu a emissão de brotações. As concentrações de 2,22, 8,88 e $11,19 \mu \mathrm{M}$ desta citocinina, promoveram as maiores taxas de multiplicação no primeiro, segundo e quarto subcultivos, respectivamente.

Palavras-chave: Etlingera elatior, 6-benzilaminopurina, micropropagação, cultura de tecidos.
\end{abstract}

\begin{abstract}
BAP concentration and subcultive number in torch ginger multiplication

The large ornamental potential of tropical flowers has stimulated the commercial cultivation of various species. Micropropagation is a viable alternate method of propagation, since it enables obtaining a higher number of seedlings with uniformity and pathogens free. The objective was to evaluate the in vitro multiplication rate of Etlingera elatior cv. Porcelana, using explants obtained from in vitro established seedling shoots, obtained from the 2 nd subcultive. The explants were inoculated in MS culture medium containing different concentrations of $\operatorname{BAP}(0.0 ; 2.22 ; 4.44 ; 6.66 ; 8.88$; and $11,10 \mu \mathrm{M})$, and the cultures maintained in a growth room with

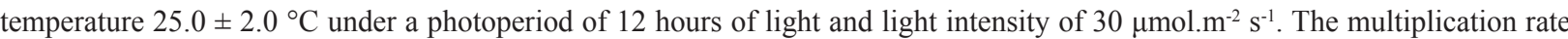
was monthly, according to the four subcultives, totaling 120 days. The experimental design was completely randomized, with four replications, analyzed in a factorial $4 \times 6$. The data were submitted to analysis of variance and regression. There were significant differences in subcultives and made for BAP concentrations used. For the first subcultive, the concentration of $2.22 \mu \mathrm{M}$ of BAP afforded a rate of 4.06 sprouts per explant, already in the second and fourth subcultives, with the addition of cytokinin concentration was increased amount of sprouts reaching at a rate of 4.05 and 4.96 shoots/explant in the highest concentration of BAP. The results of the treatments evaluated indicate that the presence of BAP favored sprout emission. The concentrations of 2.22, 8.88 and 11.10 $\mu \mathrm{M}$ this cytokinin promoted the highest multiplication rates in the first, second and fourth subcultives, respectively.
\end{abstract}

Keywords: Etlingera elatior, 6-benzylaminopurine, micropropagation, plant tissue culture.

\section{INTRODUCÃ̃O}

A floricultura é uma atividade agrícola viável economicamente para a geração de emprego e renda no Brasil, em razão da existência, em todas as regiões do País, de climas e solos apropriados para o cultivo de espécies comerciais nos principais mercados. Tem como características marcantes a possibilidade de retorno econômico rápido em pequenas áreas e de ser uma atividade típica da agricultura familiar. Apresenta grande impacto econômico-social como geradora de postos de trabalho, superando 10 empregos/ha (ROOJIEN e GEDANKEN, 2012), contribuindo para a fixação do homem no campo e ocupação das áreas com aptidão agrícola.

No segmento das plantas ornamentais para paisagismo e jardinagem, o maior índice de concentração macrorregional é encontrado na região Sudeste, que concentrou, em 2013, 60,41\% de participação porcentual relativa. É o

\footnotetext{
(1) Recebido em 27/09/2015 e aceito em 03/02/2016

(2) Universidade Federal do Ceará (UFC), CCA, Campus do Pici, Departamento de Ciências do Solo, Fortaleza-CE, Brasil.

(3) Universidade Federal do Ceará (UFC), CCA, Campus do Pici, Departamento de Fitotecnia, Fortaleza-CE, Brasil.

(4) Embrapa Agroindústria Tropical (EMBRAPA CNPAT), Laboratório de Cultura de Tecidos Vegetais, Fortaleza-CE, Brasil. *Autor correspondente: cristina.carvalho@embrapa.br
} 
segmento que mostra maior grau de dispersão geográfica, com maiores e mais significativas presenças nas demais regiões, especialmente do $\operatorname{Sul}(16,57 \%)$, no Estado do Paraná. Seguem a essas, as regiões Centro-Oeste (9,95\%), com destaque para o setor viveirista do Estado de Goiás, Nordeste $(9,51 \%)$ e Norte $(3,56 \%)$ (JUNQUEIRA e PEETZ, 2014).

O bastão-do-imperador, Etlingera elatior (Jack) R. M. Smith, pertencente à família Zingiberaceae, é originário da Malásia, e caracteriza-se por ser uma planta ornamental tropical herbácea perene e rizomatosa. Essa espécie destaca-se por seu porte exuberante e formas exóticas de suas grandes inflorescências cerosas com várias colorações, desde branca até o vermelho, incluindo vários tons de rosa. Apresenta características interessantes que levaram vários produtores a comercializá-lo como flor de corte, para composição de arranjos florais e como planta para paisagismo (LOGES, 2008; RIBEIRO et al., 2012).

Essa espécie é bastante apreciada para produção de flores cortadas, possuindo grande importância comercial (BEZERRA e LOGES et al., 2005; RIBEIRO et al., 2012). Além dos fins ornamentais, espécies do gênero Etlingera são utilizadas como alimento, condimento, medicamento, perfume, corante e óleo essencial (JAAFAR et al., 2007).

A produção de mudas in vitro é utilizada na propagação de espécies ornamentais herbáceas e arbustivas, visando à obtenção de grande número de plantas, multiplicação de híbridos com a manutenção da identidade genética, produção de mudas durante o ano todo, e rápida propagação de indivíduos resultantes de programas de melhoramento para fins comerciais. A micropropagação, além da utilização para produção de mudas em larga escala, pode também ser empregada para a limpeza clonal, ou seja, para a obtenção de plantas isentas de patógenos, principalmente vírus (GRATTAPAGLIA e MACHADO, 1998).

$\mathrm{O}$ acréscimo de reguladores de crescimento ao meio de cultivo tem como objetivo suprir possíveis deficiências endógenas e melhorar as condições de cultivo in vitro. O tipo e a concentração destas substâncias, adicionadas ao meio de cultura, são fatores determinantes no crescimento e no padrão de desenvolvimento da maioria das culturas mantidas sob estas condições (HARTMANN et al., 2002).

As citocininas são indispensáveis para a quebra de dominância apical e indução de proliferação de gemas axilares. O tipo de citocinina e a sua concentração são os fatores que mais influenciam o sucesso da multiplicação in vitro. O 6-benzilaminopurina (BAP) tem sido muito eficaz para promover multiplicação em diversas espécies. A ação desse regulador de crescimento pode ser justificada pela capacidade que os tecidos vegetais têm de metabolizar os hormônios naturais mais rapidamente do que os sintéticos (BORGES JÚNIOR et al., 2004).

No cultivo in vitro, diversos protocolos com formulações de meios básicos e diferentes concentrações e/ou combinações de reguladores de crescimento têm sido utilizados nos meios de cultura, visando adequálos às necessidades de cada espécie vegetal, estimulando respostas como crescimento, alongamento, enraizamento e multiplicação da parte aérea (ALMEIDA et al., 2002; BARBOZA et al., 2004; PAIVA et al., 2004; SILVA et al., 2008; VILLA et al., 2010), entretanto, para bastãodo-imperador existem poucos registros (RESCAROLLI e ZAFFARI, 2009; COLOMBO et al., 2010; ABDELMAGEED et al., 2011; YUNUS et al., 2012, DIAS et al., 2013).

Considerando a crescente importância das espécies do gênero Etlingera e as vantagens das técnicas aplicadas ao cultivo in vitro, torna-se necessária a realização de estudos que avaliem essas técnicas, na tentativa de solucionar o problema da demanda de mudas de bastão do imperador cv. Porcelana com alta qualidade fitossanitária e genética, em larga escala.

O presente trabalho teve como objetivo avaliar o efeito da citocinina BAP, durante quatro subcultivos sucessivos, na multiplicação in vitro de bastão do imperador cv. Porcelana.

\section{MATERIAL E MÉTODOS}

O material vegetal utilizado no experimento consistiu em brotações provenientes de mudas mantidas in vitro, obtidas a partir da cultura de ápices caulinares de bastão do imperador [Etlingera elatior (Jack) R.M. Smith] cv. Porcelana.

Os explantes, brotações, foram excisados a partir de mudas micropropagadas, oriundas do segundo subcultivo, 60 dias in vitro. Estas brotações apresentavam as seguintes características: aproximadamente $1,0 \mathrm{~cm}$ de altura e sem a presença das raízes.

A capacidade dos recipientes utilizados foi de $220 \mathrm{~mL}$, contendo $30 \mathrm{~mL}$ de meio de cultura MS (MURASHIGE e SKOOG, 1962) adicionado de diferentes concentrações de BAP $(0 ; 2,22 ; 4,44 ; 6,66 ; 8,88 ; 11,10 \mu \mathrm{M})$, de acordo com o tratamento. $\mathrm{O} \mathrm{pH}$ dos meios de cultura foi ajustado para 5,8 antes da autoclavagem, realizada a $121^{\circ} \mathrm{C}$ por 15 minutos. Foram efetuados quatro subcultivos sucessivos, a cada 30 dias, conservando-se os explantes no mesmo meio de cultura, em função do tratamento.

Os explantes foram mantidos em sala de crescimento com temperatura de $25 \pm 2{ }^{\circ} \mathrm{C}$, fotoperíodo de 12 horas de luz e intensidade luminosa de $30 \mu \mathrm{mol} \mathrm{m} \mathrm{m}^{-2} \mathrm{~s}^{-1}$. Foram inoculados três explantes, por frasco de vidro transparente, e vedados com tampas de polipropileno, em câmaras de fluxo laminar, sob condições assépticas.

O delineamento experimental utilizado foi o inteiramente casualizado, em arranjo fatorial $4 \times 6$, quatro subcultivos sucessivos (efetuados a cada 30 dias) e seis concentrações de $\operatorname{BAP}(0,0 ; 2,22 ; 4,44 ; 6,66 ; 8,88 ; 11,10 \mu \mathrm{M})$. O ensaio constou de quatro repetições, sendo a unidade experimental constituída por um frasco contendo três explantes.

Ao final de 30 dias de cultivo in vitro, após o início de cada um dos quatro subcultivos sucessivos, avaliou-se a taxa de multiplicação, isto é, contou-se o número de brotos obtidos por explante. Os dados foram submetidos à análise de variância e de regressão, por meio do software SISVAR (FERREIRA, 2011). 


\section{RESULTADOS E DISCUSSÃO}

A análise de regressão para o número de brotos em função das concentrações de citocinina testada demonstrou que esta característica foi estimulada pelo aumento da concentração do BAP. O primeiro, segundo e quarto subcultivos foram significativos com modelos polinomial quadrático e lineares respectivamente. O terceiro subcultivo não foi significativo.

Pode-se observar que no primeiro subcultivo o número de broto na concentração de $2,22 \mu \mathrm{M}$ de $\mathrm{BAP}$, promoveu o valor máximo de 4,36 brotos, indicando o efeito dessa citocinina em superar a dominância apical e a dormência das gemas laterais, promovendo o crescimento dos mesmos (LOGES et al., 2005; RESCAROLLI e ZAFFARI, 2009). Com o aumento da dosagem para $4,44 \mu \mathrm{M}$, e $8,88 \mu \mathrm{M}$ ocorreu redução na quantidade de brotações emitidas por explante com de 3,5 a 4 brotos respectivamente e menor valor obtido de 3 brotos na dosagem de 11,10 $\mu \mathrm{M}$ (Figura 1).

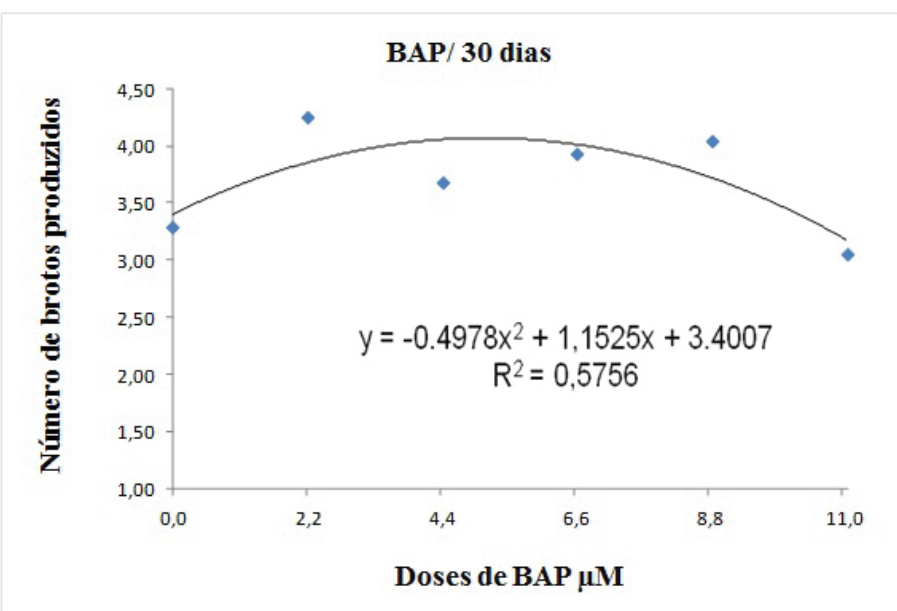

Figura 1. Curva resposta para o número de brotos/explante de bastão do imperador (Etlingera elatior) cv. Porcelana, em função da concentração da citocinina BAP em $\mu \mathrm{M}$ no primeiro subcultivo, isto é, aos 30 dias após a inoculação dos explantes in vitro.

Figure 1. Response curve for the number of shoots/explants of the torch ginger (Etlingera elatior) cv. Porcelain according to the concentration of BAP in $\mu M$ on the first subculture, 30 days after explants in vitro inoculation.

Abdelmageed et al. (2011) estudando diferentes concentrações de $\operatorname{BAP}(0,0 ; 4,4 ; 8,9 ; 13,3 ; 17,8 ; 22,2$ e 26,6 $\mu \mathrm{M})$ na multiplicação do bastão do imperador aos 56 dias in vitro, observaram que a melhor resposta foi obtida em meio MS suplementado com 22,2 uM. Até 3,67 brotos por explantes foram produzidos, mas não significativamente diferente de 4,4, 8,9 e 26,6 mM concentrações.

Os autores ressaltam que os resultados implicam que BAP como regulador de crescimento de plantas, desempenhou um papel importante na multiplicação das brotações. Da mesma forma, Rescarolli e Zaffari (2009) observaram que o maior número de brotos foram obtidos com o uso de BAP 4,44 $\mu \mathrm{M}$, o que indica a importância de regulador de crescimento de BAP na multiplicação dessa espécie.

A citocinina BAP é conhecida como hormônio para multiplicação de parte aérea das plantas e proliferação de gemas e na maioria dos trabalhos tem se procurado um balanço ideal desse hormônio para várias espécies como lenhosas (CAMPOS, 2013), medicinais (ASMAR et al., 2012), frutíferas (VIDAL et al., 2013), ornamentais (ALVES et al., 2014) dentre outras, em que a utilização das concentrações adequadas dessa citocinina potencializou a multiplicação in vitro dessas espécies.

Resultado contrário foi obtido por Pasqual et al. (2008), estudando a micropropagação de abacaxi ornamental verificaram que com aumento das concentrações de BAP $(0,0 ; 2,22 ; 4,44 ; 6,66 \mu \mathrm{M})$ em meio de cultura sem ágar, ocorreu um aumento linear no número de brotos e o número máximo brotações por explante foi alcançado quando se utilizou a maior concentração de $6,66 \mu \mathrm{M}$ do regulador.

A concentração de $6,66 \mu \mathrm{M}$ de BAP promoveu a melhor resposta para o número de brotações na micropropagação de abacaxizeiro comestível, Ananas comosus (L.) (Almeida et al., 2002). Efeito semelhante foi observado na espécie estudada, durante o primeiro subcultivo, aos 30 dias do cultivo in vitro, com variação na quantidade de brotos de acordo com cada concentração, provavelmente pelo fato da cultura ainda estar se adaptando às novas condições de cultivo.

Plantas cultivadas in vitro - frasco fechado, elevada umidade relativa, reduzido fluxo de fótons fotossintéticos apresentam folhas finas, estômatos poucos funcionais com um deficiente mecanismo de abertura e fechamento, além de apresentarem uma fraca conexão vascular entre o sistema radicular e a parte aérea (Zobayed et al., 2002).

No segundo (Figura 2) e quarto (Figura 3) subcultivos notou-se que com o aumento da concentração de citocinina, houve um crescimento considerável da taxa de multiplicação, atingindo valores de 4,05 e 4,96 brotações na maior concentração testada $(11,10 \mu \mathrm{M}$ de BAP), respectivamente. 


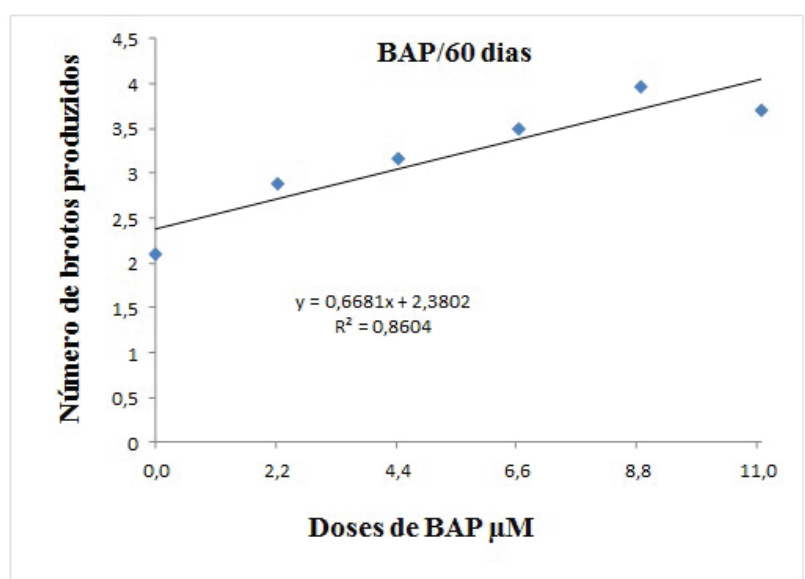

Figura 2. Curva resposta para o número de brotos/explante de bastão-do-imperador (Etlingera elatior) cv. Porcelana, em função da concentração da citocinina BAP em $\mu \mathrm{M}$ no segundo subcultivo, isto é, aos 60 dias após a inoculação dos explantes in vitro.

Figure 2. Response curve for the number of shoots/explants of the torch ginger (Etlingera elatior) $c v$. Porcelain according to the concentration of BAP in $\mu M$ on the first subculture, 60 days after inoculation of explants in vitro.

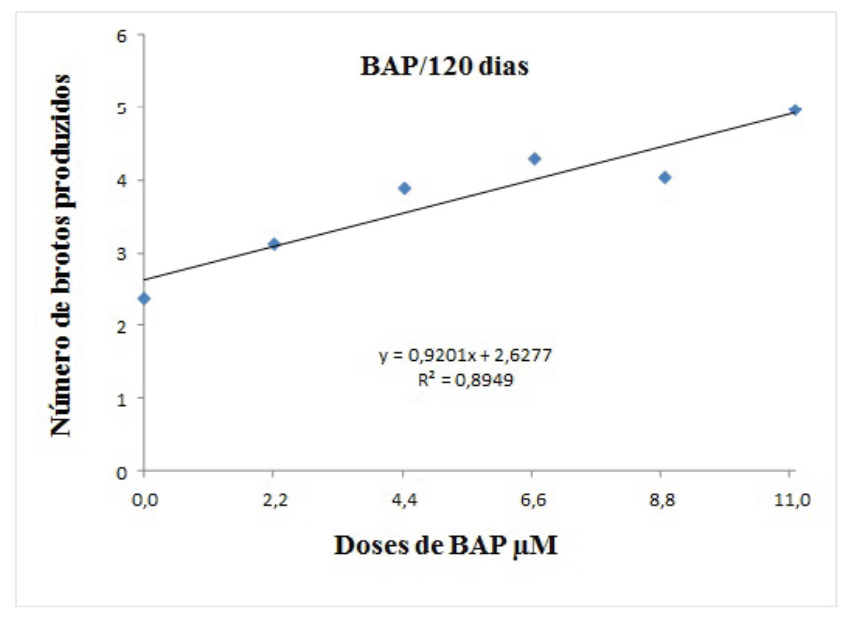

Figura 3. Curva resposta para o número de brotos/explante de bastão do imperador (Etlingera elatior) cv. Porcelana, em função da concentração da citocinina BAP em $\mu \mathrm{M}$ no quarto subcultivo, isto é, aos 120 dias após a inoculação dos explantes in vitro.

Figure 3. Response curve for the number of shoots/explants of the torch ginger (Etlingera elatior) cv. Porcelain according to the concentration of BAP in $\mu M$ on the fourth subculture, 120 days after inoculation of explants in vitro.

Resultados semelhantes foram obtidos por Ulisses et al. (2010) estudando a propagação in vitro de Heliconia bihai obtiveram uma maior média de 1, 64 e 2,33 brotos no meio MS com 100 e $50 \%$ da concentração dos sais, sem hormônio e suplementado com 11,10 $\mu \mathrm{M}$ BAP respectivamente. Os autores relatam que o número de brotos produzidos foi maior após 45 dias de cultivo com relação aos 30 dias iniciais obtendo uma taxa de 1,57 e 1,45, respectivamente, na concentração de $11,10 \mu \mathrm{M}$ de BAP.

Rodrigues et al. (2006) avaliando a propagação de mudas de helicônia em Biorreator de Imersão Temporária (BIT) também observaram que o maior número de brotações obtidas ao final dos subcultivos foi alcançado no menor intervalo entre as imersões dos explantes no meio MS acrescido de 11,10 $\mu \mathrm{M}$ BAP.
Esses resultados demonstram que o número de subcultivo é de fundamental importância para a adaptação dos explantes à nova condição estabelecida, para a detecção, o reconhecimento e a absorção da fonte exógena de regulador de crescimento e, em uma fase posterior, para a resposta ao estímulo. Portanto, o período de incubação mais comum entre repicagens é de quatro semanas, podendo este não ser o intervalo ideal para otimizar a taxa de multiplicação (GRATTAPAGLIA e MACHADO, 1998).

Colombo et al. (2010) visando o estabelecimento de um protocolo para multiplicação in vitro de bastãodo-imperador, na fase de isolamento aos 120 dias de cultivo, os autores obtiveram uma maior taxa de 2,63 brotos, quando as culturas foram mantidas em meio MS suplementado com 21,97 $\mu \mathrm{M}$ de BAP e 2,85 $\mu \mathrm{M}$ de ácido 
indolacético (AIA). Aos 90 dias de cultivo, durante a fase de multiplicação, os autores não presenciaram diferenças estatísticas entre as concentrações de BAP e combinações com ácido naftalenoacético (ANA) quanto ao número de brotações.

Da mesma forma Yunus et al. (2012) também formulando um protocolo de micropropagação de bastão do imperador testando diferentes concentrações de $\operatorname{BAP}(0 ; 13,32 ; 22,20$; 31,08 e 44,40 $\mu \mathrm{M}$ ) na indução de brotações registraram diferença significativa entre as concentrações de BAP e que o maior porcentual de explantes que formaram brotos (95\%) foram registrados no meio MS contendo BAP 13,32 $\mu \mathrm{M}$, produzindo em média 2,57 brotos. Na fase seguinte, os autores tranferiram os brotos para meio MS contendo diferentes tipos e concentrações de citocinina e verificaram maior eficiência do BAP na multiplicação dos mesmos.

Vale salientar que a taxa de brotações no presente trabalho para mesma espécie foi superior quando utilizado a menor concentração de BAP. As citocininas participam na regulação de muitos processos do vegetal, principalmente na proliferação de células vegetais, quando estas são cultivadas em meio de cultura (TAIZ e ZEIGER, 2013).

Segundo Kerbauy (2004), o ápice na planta inibe o crescimento das gemas laterais, por ação da auxina, que se movimenta de cima para baixo. Com a retirada do ápice, ou seja, com a quebra da dominância apical, as citocininas passam a acumular nas gemas laterais, promovendo o seu desenvolvimento e a formação de brotos.

O BAP tem se destacado, entre as citocininas, pela sua eficiência em induzir a formação de grande número de brotos e elevadas taxas de multiplicação em várias espécies de plantas e, por isso, tem sido a mais utilizada em trabalhos de multiplicação in vitro do que outras citocininas (CALDAS et al., 1998; GRATTAPAGLIA e MACHADO, 1998).

\section{CONCLUSÕES}

A citocinina BAP favoreceu a formação de brotações in vitro em bastão-do-imperador (Etlingera elatior) cv. Porcelana cultivada em meio de cultura MS.

As concentrações de 2,22, 8,88 e 11,19 $\mu \mathrm{M}$ desta citocinina, promoveram as maiores taxas de multiplicação no primeiro, segundo e quarto subcultivos, respectivamente, viabilizando a produção de mudas micropropagadas dessa espécie.

\section{AGRADECIMENTOS}

Agradecemos ao CNPq e a EMBRAPA pelas bolsas de estudos e pelo apoio financeiro na realização dessa pesquisa.

\section{REFERÊNCIAS}

ABDELMAGEED, A.H.A.; FARIDAH Q.Z.; NUR AMALINA A.; YAACOB, M. The influence of organ and post-harvest drying period on yield and chemical composition of the essential oils of Etlingera elatior
(Zingiberaceae). Journal of Medicinal Plants Research, Ebène, v.5, n.15, p.3432-3439, 2011.

ALMEIDA, W.A.B.; SANTANA, G.S.; RODRIGUEZ, A.P.M.; COSTA, M.A.P.C. Optimization of a protocol for the micropropagation of pineapple. Revista Brasileira de Fruticultura, Jaboticabal, v.24, n.2, p.296-300, 2002. DOI: $<$ http://dx.doi.org/10.1590/S0100-29452002000200005>.

ALVES, K.A.; LONDE, L.N.; MELO, E.F.; RODRIGUES, G.B. Multiplicação de abacaxizeiros ornamentais em diferentes concentrações de BAP e períodos de avaliação do desenvolvimento in vitro. Bioscience Journal, Uberlândia, v. 30, n. 1, p. 188-198, 2014.

ASMAR, S.A.; RESENDE, R.F.; ARARUNA, E.C.; MORAIS, T.P.; LUZ, J.M.Q. Concentrações de BAP sobre a proliferação in vitro de brotos de Lippia alba [(Mill.) N.E.Brown]. Revista Brasileira de Plantas Medicinais, Botucatu, v.14, n.esp., p.149-153, 2012. DOI: <http:// dx.doi.org/10.1590/S1516-05722012000500004>.

BARBOZA, S.B.S.C.; CALDAS, L.S.; SOUZA, L.A.C. Micropropagação do híbrido PExSC-52 e da cultivar Smooth Cayenne de abacaxizeiro. Pesquisa Agropecuária Brasileira, Brasília, v.39, n.8, p.725-733, 2004. DOI: $<$ http://dx.doi.org/10.1590/S0100-204X2004000800001>.

BEZERRA, F.C.; LOGES, V. Zingiberaceae. In: TERAO, D.; CARVALHO, A.C.P.P.; BARROSO, T.C.S.F. (Ed.). Flores tropicais. Brasília, DF: Embrapa Informação Tecnológica, 2005. p. 103-127.

BORGES JÚNIOR, N.; SOBORSA, R.C.; CODER, M. P. M. Multiplicação in vitro de gemas axilares de acácia-negra (Acacia mearnsii De Wild.). Revista Árvore, Viçosa, v.28, n.4, p.751-754, 2004. DOI: <http://dx.doi.org/10.1590/ S0100-67622004000400004>.

CALDAS, L.S.; HARIDASAN, P.; FERREIRA, M.E. Meios nutritivos. In: TORRES, A.C.; CALDAS, L.S.; BUSO, J.A. Cultura de tecidos e transformação genética de plantas. Brasília: EMBRAPA/CBAB, 1998. p. 261-296.

CAMPOS, V.C.A.; BRITO, A.L.; GUTIERREZ, I.E.M.; SANTANA, J.R.F.; SOUZA, A.V.V. Micropropagação de umburana de cheiro. Ciência Rural, v.43, n.4, p.639644, 2013. DOI: <http://dx.doi.org/10.1590/S0103$84782013005000018>$.

COLOMBO, L.A.; ASSIS, A.M.; FARIA, R.T.; ROBERTO, S.R. Estabelecimento de protocolo para multiplicação in vitro de bastão-do-imperador (Etlingera elatior) Jack RM Sm. Acta Scientiarum. Maringá, v.32, n.4, p.695700, 2010. DOI: <http://dx.doi.org/10.4025/actasciagron. v32i4.4830>.

DIAS, G.G.; PASQUAL, M.; CARVALHO, A.C.P.P. Indução de calos embriogênicos em bastão do imperador 
in vitro. Scientia Agraria Paranaensis, Marechal Cândido Rondon, v.12, n.4, p.293-300, 2013. DOI: <http://dx.doi. org/10.18188/1983-1471/sap.v12n4p293-300>.

FERREIRA, D.F. Sisvar: a computer statistical analysis system. Revista Ciência e Agrotecnologia, Lavras, v.35, n.6, p.1039-1042, 2011. DOI: <http://dx.doi.org/10.1590/ S1413-70542011000600001>.

GRATTAPAGLIA, D.; MACHADO, M.A. Micropropagação. In: Técnicas e aplicação da cultura de tecidos de plantas. In: TORRES, A.C.; CALDAS, L.S. (Ed.). Brasília: EMBRAPA/CNPH.1998. 509p.

HARTMANN, H.T.; KESTER, D.E.; DAVIES, F.T.; GENEVE, R.L. Plant Propagation: Principles and Pratices. 7 ed. New Jersey: Prentice Hall, 2002. 880p.

JAAFAR, M.F.; OSMAN, C.P.; ISMAIl, N.H.; AWANG, K. Analysis of essential oils of leaves, stems, flowers and rhizomes of Etlingera elatior (Jack) R.M. The Malaysian Journal of Analytical Sciences, Selangor, v.10, n.1, p.269-273. 2007.

JUNQUEIRA, A.H.; PEETZ, M.S. O setor produtivo de flores e plantas ornamentais do Brasil, no período de 2008 a 2013: atualizações, balanços e perspectivas. Revista Brasileira de Horticultura Ornamental, Campinas, v.20, n.2, p.115-120, 2014.

KERBAUY, G.B. Fisiologia vegetal. Rio de Janeiro: Guanabara Koogan, 2004. 452p.

LOGES, V.; COSTA, A.S.; GUIMARÃES, W.N.R.; TEIXEIRA, M.C.F.; Potencial de mercado de bastão-doimperador e sorvetão. Revista Brasileira de Horticultura Ornamental, Campinas, v.14, n.1, p.15-22, 2008. DOI: $<$ http://dx.doi.org/10.14295/rbho. v14i1.225>.

LOGES, V.; TEIXEIRA, M.C.F.; CASTRO, A.C.R., COSTA, A. Colheita, pós- colheita e embalagem de flores tropicais em Pernambuco. Horticultura Brasileira, Brasília, v.23, n.3, p.699-702, 2005. DOI: < http://dx.doi. org/10.1590/S0102-05362005000300001>

MURASHIGE, T.; SKOOG, F. A Revised medium for rapid growth and bioassay with tobacco tissue cultures. Physiologia Plantarum, Copenhagen, v.15, n.3, p.473-497, 1962.

PAIVA, P.D.O.; PAIVA, R.; PASQUAL, M.; PAIVA, L.V. Estabelecimento in vitro de Estrelícia (Strelizia reginae Banks). Ciência e Agrotecnologia, Lavras, v.28, n.5, p.1031-1037, 2004. DOI: <http://dx.doi.org/10.1590/ S1413-70542004000500009>.

PASQUAL, M.; SANTOS, F.C.; FIGUEIREDO, M.A.; JUNQUEIRA, K.P.; REZENDE, J.C.; FERREIRA, E.A. Micropropagação do abacaxizeiro ornamental. Horticultura Brasileira, Brasília, v.26, n.1, p.4549, 2008. DOI: <http://dx.doi.org/10.1590/S010205362008000100009>.
RESCAROLLI, C.L.S.;ZAFFARI, G.R. Produção de mudas de Etlingera elatior (Jack) R.M. Sm. através da cultura de tecidos vegetais in vitro. Revista Brasileira de Plantas Medicinais, Botucatu, v.11, n.2, p.190-195, 2009. DOI: $<$ http://dx.doi.org/10.1590/S1516-05722009000200013>.

RIBEIRO, T.R; ALMEIDA, E.F.A.; FRAZÃO, J.E.; CARVALHO, J.G. Bastão-do-imperador. In: PAIVA, P.D.O; ALMEIDA, E.F.A. (Ed.). Produção de flores de corte. Lavras: UFLA, 2012. p. 90-103.

RODRIGUES, P.H.V.; TEIXEIRA, F.M.; LIMA, A.M.L.P.; AMBROSANO, G.M.B. Propagação de mudas de helicônia em biorreator de imersão temporária. Bragantia, Campinas, v.65, n.1, p.29-35, 2006. DOI: <http://dx.doi. org/10.1590/S0006-87052006000100005>.

ROOIJEN, S. VAN; GEDANKEN, A. Capacitação tecnológica em flores e plantas ornamentais. Brasília: Serviço Nacional de Aprendizagem Rural (SENAR) e CNA Brasil, 2012. 9p.

SILVA, A.L.L.; FRANCO, E.T.H.; DORNELLES, E.B.; GESING, J.P.A. Micropropagação de Dyckia maritima Baker - Bromeliaceae. Iheringia, Série Botânica, Porto Alegre, v.63, n.1, p.135-138, 2008.

TAIZ, L.; ZEIGER, E. Fisiologia vegetal. 5 ed. Porto Alegre: Ed Artmed, 2013. 918 p.

ULISSES, C.; PINNA, G. F. M.; WILLADINO, L.; ALBUQUERQUE, C.C.; CAMARA, T. R. In vitro propagation of Heliconia bihai (L.) L. from zygotic embryos. Acta Botanica Brasilica. Feira de Santana, v.24, n.1, p.184-192. 2010. DOI: http://dx.doi.org/10.1590/ S0102-33062010000100018.

VIDAL, F.R.; DINIZ, J.D.N.; SILVA, F.P. Multiplicação in vitro de plantas juvenis de mamoeiro. Pesquisa Agropecuária Tropical, Brasília, v.43, n.1, p.6470, 2013. DOI: <http://dx.doi.org/10.1590/S198340632013000100010>.

VILLA, F.; PASQUAL, M.; SOUZA, A.G.; VILELA, X.M.S. Meios de cultura e reguladores de crescimento na multiplicação in vitro de amoreira-preta. Scientia Agraria, Curitiba, v.11, n.2, p.109-117, 2010.

YUNUS, M.F.; ABD AZIZ M.; KADIR, M.A.; RASHID, A.A. In vitro propagation of Etlingera elatior (Jack) (torch ginger). Scientia Horticulturae, Amsterdam, v.135, n.24, p.145-150, 2012.

ZOBAYED, S.M.A.; ARMSTRONG, J.; ARMSTRONG, W. Multiple shoot induction and leaf and flower bud abscission of Annona cultures as affected by types of ventilation. Plant Cell, Tissue and Organ Culture, v.69, n.2, p.155-165, 2002. DOI: <10.1016/S01689452(01)00438-1>. 